\title{
Cultivate Students' Divergent Thinking in Total Differential Teaching
}

\author{
Wang Yan ${ }^{1, a}$ \\ ${ }^{1}$ Nanchang Institute of Science and Technology, Nanchang 330108, China \\ awangyan@126.com
}

Keywords: Binary compound function; Partial derivatives. Total differential; The chain guide laws; Implicit function derivation method

\begin{abstract}
Under the background of popularization of education, college students' ability on entry is generally lower, the student level more and more uneven, which have become a major problem the world's higher education facing. Reform of basic education course in the making, on the other hand, make great changes have taken place in the secondary school curriculum, which also put forward new requirements for university curriculum. Popular university education and high school curriculum reform background make calculus teaching problem increasingly prominent. Many college students will be derivative and integral operation, but the concept contains thought was not understood. So, it is the key to find out cognitive conceptual difficulty of the students in the calculus and conduct targeted teaching design reform.
\end{abstract}

\section{The teaching of calculus concept}

Some scholars discussed: the students are good at calculus problem solving but conceptual understanding is not deep. Many a mathematician and math educators to the high school calculus teaching learning situation is not optimistic, they worry that only emphasizes calculation and ignore the teaching of the concept of get in the way of university teaching of calculus. [1] On the premise of teaching time is limited, the concept of students understanding and skills development seems to be a pair of contradiction. How to teach calculus concepts effectively? Teaching concept of calculus is the focus in the next section.

\subsection{Intuitive approach}

Many mathematicians and mathematics educator put great importance to the thought of "intuitive". In April 1966, the application of the famous American mathematician, historian in mathematics, mathematical educator $\mathrm{m}$. klein (Morris Kline) published in the journal of mathematics teachers of high school mathematics curriculum proposal, stressed that "don't put the mathematics speaks as closely as possible to portray it as much as possible to accept by instinct" (Kline, 1962). Klein in 1967 completed the method of differential and integral Calculus: visual and Physical (Calculus dissuade: An intuitive and Physical that KlineM., 1998) - a book, the book's subtitle is "intuitive and Physical methods," he said in the preface: "this Approach (intuitive and Physical methods, the author note) is especially suitable for Calculus textbooks, because Calculus is itself from the Physical and geometric problems. These problems tell us what should use function, the concept and development of the skills of how to define what".

\section{2 Method of history}

In the 20th century $60 \mathrm{~s}$ in the presence of a university campus "new movement" in the beginning of student's study proposes strict mathematical concepts, which makes the students' learning had obvious just hard, in order to deal with problems arising from the "new movement", in teaching method (the based approach to would the and learning) arises at the historic moment. 1962, klein, poly a (Kline, M., Polya, Getal., 1962) and others joined more than 70 a mathematician and math educators in the United States and Canada, published in the journal of the American mathematical force, the article titled "about the high school mathematics course", points out that not from the history background of mathematics learning mathematics in isolation, should blend in math concepts and the study of the theory of its historical development process, namely the method: "the best way to guide individual intelligence development is to follow the history of the 
development of ethnic follow its main stages, and, of course, not repeat that thousands of false details". [2]A year later, The university of Chicago press for The first time in The United States published toeplitz method of Calculus: occurrence (The Calculus dissuade: A based Approach). Below will be the main XuJi toeplitz, poly a, Klein argument to the method of History and application, and briefly introduces our country's HPM (History and Pedagogy of Mathematics).

\subsection{Learning environment that "based on the concept"}

Wood Pyle at Colorado state university (Chappell, K.K., 2003 a, 2003 b, 2006) adopted the quantitative research and qualitative research method, research the education environment (or traditional) based on concept teaching concept, application skills to students, the influence of the migration ability, etc. Around the concept of teaching Chappell, and three related experiments were conducted in the autumn of 1998 the first experiment, including 305 college students and eight teachers; In order to avoid the result of chance, in the autumn of 1999 and a second experiment, including 303 college students and eight teachers. Two rounds of research Gui conclusions are consistent. [3]In addition, the author also respectively in 1999 and 2000 spring semester for the subsequent research Gui, analysis of students' transition from based on the concept of environment to the traditional teaching environment when facing difficulties. On the basis of these research Gui, ran a third experiment, the experiment highlights the two classes of the balance of the number of teachers in teaching and teachers' teaching level, the design of quantitative and qualitative research Gui more careful, such as quantitative study please the teacher to subject classification, etc. This series of experiments, make the conclusion more scientific, avoiding the differences in the levels of teachers and students the accident caused by the results.

\section{Related research about the divergent thinking training}

\subsection{Definition of divergent thinking}

According to Guildford, point of view, and divergent thinking is the use of different direction of thinking, is not subject to the scope of existing knowledge, do not follow the traditional fixed method, and adopt the mode of open and differences, to derive various possible answers or solutions. About divergent thinking in our country, there are several different points of view, representative are: (1) the divergent thinking as a form of thinking quality, flexibility of thinking quality, can also be called the divergent thinking. (2) The divergent thinking, as a form of thinking, in the form of thinking, the thinking of pointing into concentrated thinking and divergent thinking. In contrast, the author compared with the former, divergent thinking, as a form of thinking, it has the general features of thinking, and flexibility can only as a general feature of one of them.

\subsection{History of divergent thinking}

Divergent thinking research began in the United States, a psychologist at Guildford, published in 1959, the quality of the "creativity", he is studying the thinking quality, and this paper studies the flexibility, divergent thinking and creativity, and thought of creative thinking is the heart of divergent thinking. But he failed and education practice, only stay on pure theoretical research. After more than ten years, Europe and the United States psychologists on the basis of further research, begin to pay attention to the training of experiment research, such as claims that, from the perspective of the education, since the childhood to cultivate creative thinking, divergent thinking, in particular, but this is mostly for young children's test, little research on primary school children and adolescents, basic education and the first line. In the Venezuela in South America in the $1980 \mathrm{~s}$ opened the course of "thinking" in order to cultivate student's creativity. The United States, Canada and other countries also have had a lot of research about thinking training course. After our country from the slogan put forward quality education, innovation education is mentioned the important position, become to implement innovation education to foster the creative thinking is an important aspect of the mouth. Research on creativity and its training, can be divided into two categories: a class of effective creativity for the development of measurement tools, such as Zhang De embroidery created the potential test of creative thinking, such as ri-chang zheng compiled "test for the creativity of middle school students"; Another type of research is to explore the effective ways to foster creativity, wu-sheng zhang, for example, high and curriculum, zhang jie, Yang Mengping 
and others work. Based on the point of Guildford, divergent thinking as the core of the creative thinking is widely attention; the country appeared to give priority to the divergent thinking training of primary and middle school students[4].

\subsection{Application example}

To get the total differential: $z=\cos \frac{y}{x} \sin \frac{x}{y}$.

[method 1] take $z$ as product of $\cos \frac{y}{x}$ and $\sin \frac{x}{y}$

$z_{x}^{\prime}=\left(-\sin \frac{y}{x}\right)\left(-\frac{y}{x^{2}}\right) \sin \frac{x}{y}+\cos \frac{y}{x} \cdot\left(\cos \frac{x}{y}\right) \cdot \frac{1}{y}$

$z_{y}^{\prime}=\left(-\sin \frac{y}{x}\right)\left(\frac{1}{x}\right) \sin \frac{x}{y}+\cos \frac{y}{x} \cdot\left(\cos \frac{x}{y}\right) \cdot\left(-\frac{1}{y^{2}}\right)$

[method 2] Use the differential form invariance

$\left.d z=-\sin \frac{y}{x} \sin \frac{y}{x} \cdot d\left(\frac{y}{x}\right)+\cos \frac{y}{x} \cdot \cos \frac{x}{y}\right) \cdot d \frac{x}{y}$

Among which,

$d\left(\frac{y}{x}\right)=\frac{y}{x^{2}} d x+\frac{1}{x} d y$

$d\left(\frac{x}{y}\right)=\frac{1}{y} d x-\frac{x}{y^{2}} d y$

[method 3] Use composite function chain rule

Suppose $u=\cos \frac{y}{x} ; v=\sin \frac{x}{y}$

Then $z=u \cdot v \quad z_{u}^{\prime}=u \quad z_{u}^{\prime}=v$

$u_{x}^{\prime}=-\frac{y}{x^{2}} \cos \frac{y}{x} \quad v_{x}^{\prime}=\frac{1}{y} \cos \frac{x}{y}$

\section{The methods and strategies to cultivate divergent thinking}

\subsection{Update teaching ideas; cultivate the habit of students' divergent thinking}

Intuition and mathematical knowledge inference is one of two ways, insight into nature is a major way of seeking information or gaining knowledge of mathematics. New learning science thought, meaning "knowledge (knowing)" has turned away from memory and repeat information can be found and the use of information (Simon, 1996).

Traditional teaching is to acquire knowledge through practice and memory, the new idea: based mainly on the students' learning of mathematics teaching of all students can learn the math, they need more conducive to the development of thinking, cultivating ability, therefore, to develop students' thinking ability, must renew the idea in the first place. Teachers should have the consciousness of cultivating students' divergent thinking ability, this is the guiding ideology of training innovative talents; More divergent thinking enlightenment and become a wise strategy of knowledge, this is a math class is full of vitality, a source of constant innovation and development. In class, the teacher must based on the development of the students in particular, the development of thinking, and actively implement heuristic, research type, discussion-based education, to inspire students' independent thinking and innovation consciousness, cultivate the students' scientific spirit and innovative thinking habit.

\subsection{Construct divergent point; train students' divergent thinking}

Mathematics the basic concepts, basic theorem is the foundation of mathematics, it is also the difficult point in mathematics, understand the concept is to grasp the starting point of the teaching material. Need to be able to seize them, sheet is literally understood even know, little value, it is 
important to understand them accurately; the standard is the depth of understanding, which is the result of systemic profundity. Too essentially to achieve mastery through a comprehensive study, therefore, have to know them from the perspective of system. [5]And in the process of teaching, a proper presentation of the concept of transformation, or through the discrimination of the concept of variable type, is to understand and grasp the concept, the important channel to cultivate divergent thinking. Especially in the search for the structure of the error variable type counterexample, more divergent thinking can be shown. Students enter high school, due to the development of self-awareness, in obtaining their predecessors summary of experience at the same time, also often have their own new views, or trying to further development of predecessors' achievements. Even if the structure of the students is wrong, as a teacher to guide students in the process of positive thinking, make its natural "dissonance". In this process, the structure of thinking though failed, but it is the forerunner of success. Gradually in the teaching practice, therefore, to establish a concept centered divergent problem, lets the student in the participation constantly enrich their own ideas, cultivate and promote students' divergent thinking ability.

\subsection{Train students' divergent thinking through exercises training,}

In the process of mathematics teaching, the teacher may in combination with the practical situation of teaching content and students, adopt various forms of exercise training, cultivating students' thinking agility and flexibility, spread to induce students' thinking, the purpose of the cultivation of divergent thinking.

\subsubsection{More than a problem solution}

Fluency reflects the characteristics of speed and number of divergent thinking. It can be used per unit time the number of answer questions or to generate new ideas calculated on the basis of the number of new ideas. We call this amount of divergent thinking, and how much of it is based on the accumulation of knowledge. The rich knowledge, observation, analysis, analogy, lenovo's space is open, new ideas, new concepts, new methods, new rules to produce the more opportunities. In the teaching, training more than a problem solution to the student, can improve the students' thinking divergence, which benefits the fluency of thinking.

The so-called "more than a problem solution" is on the basis of the conditions and problems, lets the student multiple perspectives, analytical thinking, multi-side to find different way to solve problems. In this case, the students often get the new way to solve the problem. After such training of students, not only has high flexibility of thinking, but also have strong strain capacity, can full and accurate grasp of knowledge, and form the habit of multi-angle analysis to solve practical problems, and to explore the unknown. As a result, more than a problem solution is an effective way of training students' divergent thinking.

\subsubsection{More than a problem}

Novelty and originality of thinking that is thinking in the teaching using more than one topic, blend in a variety of teaching methods, encourage students to think independently, find and solve problems that others have been found and, can get new knowledge, self-study discussion found new problems.

"More than a question about" refers to provide some mathematics situation, to mobilize students' various old knowledge skills or experience, group discussion, cause thinking spark collision. This is from the perspective of students' cognitive process, in order to broaden the train of thought as the guide, guided thought gradually deepening, to gradually deepen, establish to achieve the goal that follow. It can effectively cultivate thinking profundity and originality.

\section{Summary}

Divergent thinking training can help students gradually overcome the influence of mindset, enable students to from a new angle to solve the problem that others don't notice, thus cultivate students' ability to consciously use the divergent thinking. Exert students' main body status, make the students' divergent thinking and creative thinking inspired gradually and deepen ceaselessly, full play to their potential of thinking, thus improve the comprehensive quality of students. 


\section{References}

[1] Guan Hongbin. Construct the divergent point: cornerstone of the divergent thinking ability training, the study of mathematics teaching, 2016.

[2] Li Yuanshou. Thinking training (second edition), Huazhong university of science and technology press, 2014.

[3] Xiong Changming. Training students' divergent thinking ability in mathematics teaching, Journal of sichuan college of education, 2015.

[4] Liu Yongjun. Use of classroom teaching to cultivate divergent thinking. Journal of institute of education of the corps, 2015.

[5] Chenqi. Some thoughts about computer assisted instruction. Journal of Beijing normal university (social science edition), 2013. 